Divertor Design for the Tokamak Physics Experiment*

D. N. Hill, T. Kaiser

M. E. Rensink, T. D. Rognlien

Lawrence Livermore National Laboratory

B. Braams

Courant Inst. NYU

J. N. Brooks

Argonne National Laboratory

D. N. Ruzic

University of Illinois

M. Ulrickson, R. Campbell

Sandia National Laboratories

K. A. Werley

Los Alamos National Laboratory

R. Goldston

Princeton Plasma Physics Laboratory

G. H. Neilson, P. Mioduszewski

Oak Ridge National Laboratory

This paper was prepared for

11th International Conference on Plasma Surface

Interactions in Controlled Fusion Devices

Mito-Shi, Ibaraki-Ken, Japan

May 23-27, 2994

May 1994

This is a preprint of a paper intended for publication in a journal or proceedings. Since changes may be made before publication, this preprint is made available with the understanding that it will not be cited or reproduced without the permission of the author. 


\section{DISCLAIMER}

This document was prepared as an account of work sponsored by an agency of the United States Government. Neither the United States Government nor the University of California nor any of their employees, makes any warranty, express or implied, or assumes any legal liability or responsibility for the accuracy, completeness, or usefulness of any information, apparatus, product, or process disclosed, or represents that its use would not infringe privately owned rights. Reference herein to any specific commercial products, process, or service by trade name, trademark, manufacturer, or otherwise, does not necessarily constitute or imply its endorsement, recommendation, or favoring by the United States Government or the University of California. The views and opinions of authors expressed herein do not necessarily state or reflect those of the United States Government or the University of California, and shall not be used for advertising or product endorsement purpose. 


\section{DISCLAIMER}

Portions of this document may be illegible in electronic image products. Images are produced from the best available original document. 


\title{
Divertor Design for the Tokamak Physics Experiment
}

\author{
D.N. Hill, B. Braams, a J.N. Brooks ${ }^{b}$ D.N. Ruzic.c M. Ulrickson, d K. A. Werley.e
}

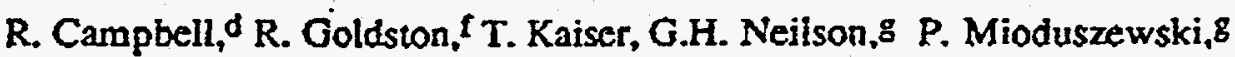

M.E Rensink, and T.D. Rognlien,

Lawrence Livermore Nacional Laboratory, P.O. Box 5511. Livermore, California, 94550

\begin{abstract}
In this paper we discuss the present divertor design for the planned TPX tokarnak, which will explore the physics and technology of steady-state (1000s pulses) heat and particle removal in high confinement $\left(2-4 \times\right.$ L-mode), high beta $\left(\beta_{\mathrm{N}} \geq 3\right)$ divertor plasmas sustained by non-inductive current drive. The TPX device will operate in the double-null diverwor configuration, with actively cooled graphite targets forming a deep $(0.5 \mathrm{~m})$ slot at the outer strike point. The peak heat flux on the highly tilted (740 from normal) re-entrant ( 10 recycle ions back toward the separatrix) will be in the range of $4-6 \mathrm{MW} / \mathrm{m}^{2}$ with $18 \mathrm{MW}$ of neutral beam and RF heating power. The combination of active pumping and gas puffing (deuterium plus impurities), along with higher heating power (45 MW maximum) will allow testing of radiative divertor concepts at IIER-like power densities.
\end{abstract}

-Work was performed under the auspices of the U.S. Department of Energy by Lawrence Livermore National Laboratory under Contract W-7405-ENG-48 and by General Atomics under Contract DEAC02-76-CHO-3073.

aCourant Instivten NYU, bArgorne National Laboratory. "University of Illinois. ISandia National Laboralories, CLos Alamos National Laboratory, 'Princeton Plasma Physics Laboratory,

BOak Ridge National Laboratory. 


\begin{tabular}{|l|l|l|}
\hline Plasma volume $=20 \mathrm{~m}^{3}$ & Plasma surface area $\approx 60 \mathrm{~m}^{2}$ & $\begin{array}{l}\text { Total divertor contact } \\
\text { area }=1.2 \mathrm{~m}^{2}\end{array}$ \\
\hline $\mathrm{P}=18 \mathrm{MW}$ & $\left\langle n>_{\mathrm{e}} \geq 5-6 \times 10^{19} \mathrm{~m}^{-3}\right.$ & $\mathrm{Z}_{\mathrm{eff}} \leq 2$ \\
\hline
\end{tabular}

We have adopted a conservative design for the TPX divertor, as shown by the cross section of the lower divertor in Fig. I. The double-null (DN) configuration desired for MHD stability at high elongation has the advantage that it minimizes the power and particle flux at the inner target. where access is difficult for placement of large cooled structures in highly triangular discharges. At the outer target an inclined plate ( $74^{\circ}$ from normal to the separatrix flux surface) maximizes the surface area available for heat removal so that no radiative divertor operation is required except at the highest heating powers. The central baffle in the private region helps gas (fuel plus any impurities) stay trapped near the outer target and improves particle exhaust by minimizing back-streaning from the pumping plenum. Feedback control of the particle throughput (for density control and regulation of divertor radiation) is obtained by slightly shifting the separatrix inercept relative to the plenum entrance slot or by throuling the external vacuum pumps. All of the plasma facing surfaces shown will consist of carbon fiber composites to minimize their suseptibility to irreparable damage from higher than expected heat loads due to disruptions or edge misalignment. Finally, the inclusion of gas valves for deuterium or impurity gas puffing will allow us to increase local radiative cooling of the SOL plasma in order to operate at the highest heating powers.

In the remainder of this paper we will discuss the physics basis for the design choices. Section 1. the hardware implementation in Section 2, and plans for radiative divertor operation in Section 3.

\section{Expected parameters for divertor operation}

The operating points used for the divertor design are based modeling of the scrape-off layer plasma using 1-d (NEWT-1d) and 2-d (LEDGE, b2, b2.5) codes [2], along with Monte Carlo 
simulation of the neutral gas transport (DEGAS). Both double null and single nuil configurations were examined; in the case of DN plasmas, only the lower half of the plasma was simulated. The peak heat flux predicted by the simulations was also compared with interpolation/extrapolation of data from the DIII-D and JT-60U tokamaks. Overall, this approach is very similar to that of the ITER CDA team [3]; in fact, many of the simulations were carried out by the same people in the U.S. who worked on the ITER design.

The models require certain input assumptions, which we list in Table 2. starting with the input power and fraction lost due to radiation. The distribution of power among the four divertor targets is based on DN data from PDX. ASDEX, and DIII-D experiments. The column labeled ITER represents the assumptions of the ITER CDA team applied to TPX. ELMing H-mode conditions were generally assumed (e.g., $n_{\text {sep }} /<n_{e}>=0.33, P_{\text {radicore }} / P_{\text {heal }}=0.30$, so that $P_{\text {SOL }} / P_{\text {heat }}=0.70$ ). The radial transport coeffients $D_{1}$ and $x_{e, i}$ used here span the mange reported from model validation work by various tokamak groups, though more recently. smaller values in the range of $0.1-0.5$ $\mathrm{m}^{2} / \mathrm{sec}$ have been reported by the DIII-D group [4]. In general, the models show that $\hat{q}_{\text {div }}$ increases as $1 / \sqrt{x_{e}}$, if $x_{e}$ alone is changed, but the new DII-D modeling is not producing higher divertor heat fluxes than they did previously, most likely because they are now computing the local radiativie losses due to carbon in the SOL plasma.

Table 2. Input assumptions for TPX divertor modeling

\begin{tabular}{|c|c|c|}
\hline Parameter & $\begin{array}{c}\text { ITER CDA Assumptions } \\
\text { Applied to TPX }\end{array}$ & Range of TPX Simulations \\
\hline$P_{\text {hear }}(\mathrm{MW})$ & 18 to 45 & 18 to 30 \\
\hline $\mathrm{P}_{\mathrm{SOL}}{ }^{*}(\mathrm{MW})$ & 4.7 to 11.9 & $1.8-21$ \\
\hline$P_{\text {div,out }} / P_{\text {div,in }}$ & $4 / 1$ & $2 / 1^{+}+04 / 1$ \\
\hline$n_{\operatorname{esep}}\left(10^{20} \mathrm{~m}^{-3}\right.$ & $0.157\left(\pi_{e}>/ 3\right)$ & $0.165-0.60$ \\
\hline$z_{\text {eff }}$ & 1.84 & 1.67-2.0 \\
\hline$x_{e}, x_{i}\left(m^{2} / s\right)$ & $2,0.67$ & $1-4,0.67-2.7$ \\
\hline
\end{tabular}




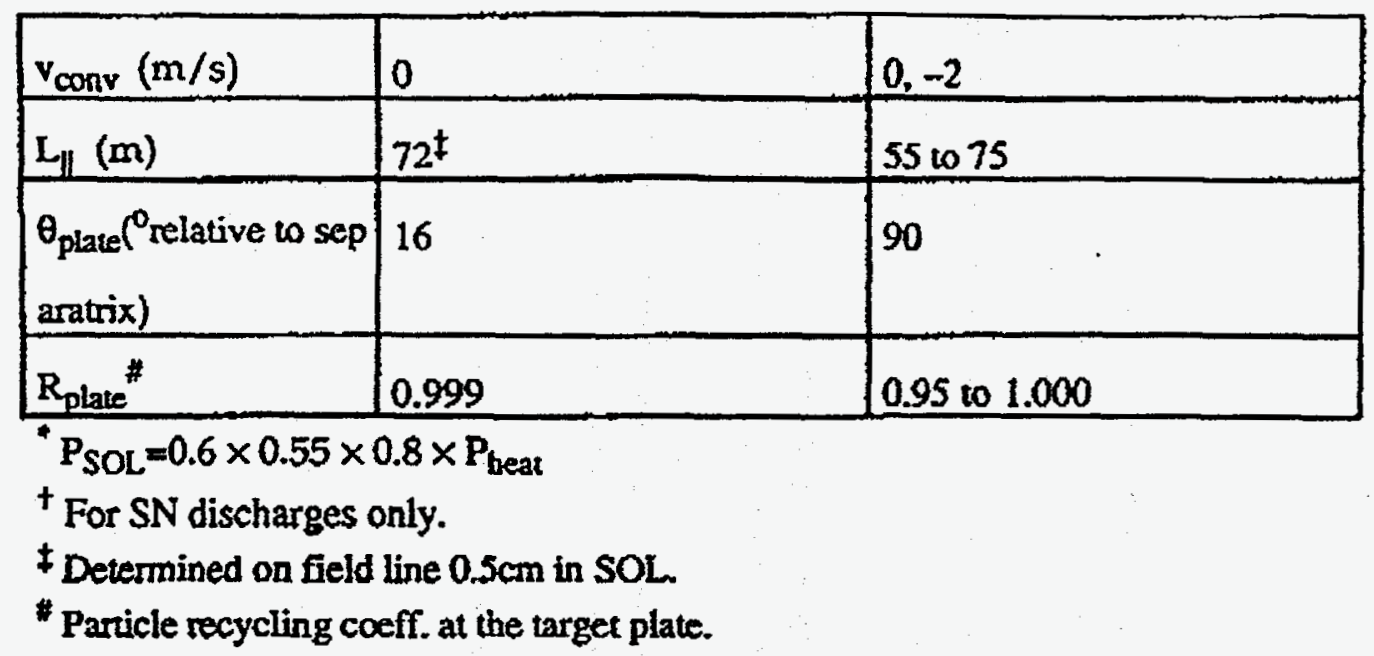

The plasma density on the separatrix is a very important factor for determining the peak heat flux and electron temperature at the divertor targets, so we have based our assumption in Table 2 on the published data for ELMing H-mode discharges [5]. Low density on the spearatrix implies high edge temperatures, high parallel thernal conductivity, and a narrow serape-off layer. IPX current drive experiments will require operation at relatively lower density than is usually obtained in $\mathrm{H}$-mode discharges $\vec{n}_{e}=0.4 \times \vec{n}_{\text {Grectwald }}$ vs $\vec{n}_{e}>0.5-0.8 \times \bar{n}_{\text {Greenwald. Recent experiments in }}$ DIII-D with divertor cryopumping have achieved such densities and have observed an increase in $\mathrm{T}_{e}$ on the separatrix near the midplane and at the inner suike point in a single-null configuration [6]. However, they sill repont that $n_{\text {sep }} / \bar{n}_{e}=0.33$ with pumping, as we have used here.

The numerical simulations show that acceptable divertor conditions $\left(T_{e d i v}=40 \mathrm{eV}\right.$, and $\hat{q}_{\text {div }}=$ $4-6 \mathrm{MW} / \mathrm{m}^{2}$ ) should be obtained in the TPX divertor when running non-inductive current drive experiments with the baseline heating power of $18 \mathrm{MW}$. Figure 2(a) shows the $\mathrm{n}_{e, d i v}, \mathrm{~T}_{\mathrm{ediv}}$ and qdiv profiles across the outer divertor target for such a discharge. Here we have expanded the radial seale to account for the $74^{\circ}$ plate till, since the b2 simulations are presently operating with orthogonal target plates. The variation of $\mathbf{n}$ and $\mathrm{T}$ along a SOL field line just outside the separatrix appear in 2(b). These results were confirmed with a similar set of LEDGE nuns. We do not show the profites at the inner target because the simulations cannot account for the in/out asymmetry in 
power seen in the experiments, most probably due to the fact that we use uniform radial transport coefficients along the whole separatrix and are not including locali impurity radiation.

Comparison between the numerical simulations and experimental data suggest that the codes give pessimistic results for the predicted TPX diveror heat flux. In this regard, we are fortunate that the initial heating power planned for TPX falls within the range already achieved on DHI-D, JET, and JT-60U, and the magnetic field is below that of Alcator C-mod, so relevant data exists, at Ieast for higher density discharges. Itami has published [7] a scaling relation for the peak heat flux in $\mathrm{T}-60 \mathrm{U}$ single-null discharges, as has Hill for DIII-D discharges [S]. If we apply their results to TPX, correcting for the differences between the DN and SN SOL power distribution, we obtain 3 $\mathrm{MW} / \mathrm{m}^{2}$ and $25 \mathrm{MW} / \mathrm{m}^{2}$ from the JT-60U and DIII-D scalings, respectively; these are somewhat lower than our simulations would predict. Now that Alcator C-mod is nuning. we have SOL data at higher magnetic fields (5Tesla); they find a density fall-off length of Xmm, which is broader than expected assuming a Bohm-like (T/B) scaling of the diffusion coefficient. As far as the in/out and up/down diseribution in double-null plasmas, the only recent data is from DIII-D. which has reported that the peak heat flux on the inner target is less than 10\% of that at the outer [8]. Earlier data from ASDEX and PDX showed a 4:1 outin power split for DN plasmas [9].

\section{Hardware design and capability}

The actively-cooled plasma facing components in TPX will be made from carbon fiber composite graphite. The centerpost armor consists of carbon tiles bolted to a cooled titanium substrate with a power handling capability of about $1 \mathrm{MW} / \mathrm{m}^{2}$. The outer toroidal limiters located above and below the plasma midplane actually form part of a conducting shell added to improve MHD stability and as strch, we have carbon tiles fastened to a copper structure. The vertical straps which connect the apper and lower parts of this shell will form a set of descrete polidal limiters. The entire limiter structure can be used for plasma startup and rampdown. 
The divertor structure in TPX is designed primarily to spread the heat flux over as large an area as possible. The vertical alignment of both the inner and outer target plates accommodate a wide range of plasma elongation and triangularity and provide a "re-entrant" configuration for recycling so that neutrals are retumed to regions of higher plasma density and ionization probability, and will thus stay better trapped in the divertor region. We have designed it so that field lines well into the scrape-off layer ( $2 \mathrm{~cm}$ midplane equivalent) still strike on the vertical surface. The nominal distance from the $x$-point to the strike point is $0.57 \mathrm{~m}$. This divertor shape will also allow for considerable variation in flux expansion near the $x$-point produced by changes in the plasma current profile (internal inductance). Details of the proposed design can be found in Ref. [10].

The high heat flux surfaces on the outer divertor target should handle $7.5 \mathrm{MW} / \mathrm{m}^{2}$ peak steady state heat flux. The inner target and central divertor baffle have a design limit of $4 \mathrm{MW} / \mathrm{m}^{2}$, set by the expected maximum radiative heat flux (45 $\left.\mathrm{MW} \times 0.7 \times 0.5+(2 \pi \times 2 \mathrm{~m})+(2 \pi \times 0.12 \mathrm{~m})=1.7 \mathrm{MW} / \mathrm{m}^{2}\right)$. At the design limits, the surface temperature will be about $14000 \mathrm{C}$ for the outer target tiles, which will consist of carbon blocks brazed onto a water-cooled copper tube fastened to a removable support structure. The design of the cooling system is such that, if the peak heat flux exceeds the design limizs by a factor of two or more, catastrophic failure should not resuit because the graphite surface will ablate and limit the temperature rise before there is bulk coolant boiling. The design limits for the outer target are about $50 \%$ below the predicted peak divertor heat flux for the initial operation.

The need to provide remote handling capability is an important element for the TPX first wall design, since the expected neutron flux and pulse length will quickly make human access impractical. Present plans call for the use of two pairs of remote manipulator arms traveling on rails mounted behind the toroidal limiters. These manipulators will be able to replace the plasma facing components such as the limiters, divertors, and centerpost armor tiles. In order to fit through the access ports, the divertor modules consist of two major parts: the outer target and the inner target/central baffle. All the high heat flux components will be mounted to internal 
continuous rails to ensure reproducible alignment relative to the magnetic field. The remote maintenance hardware will be tested early in the operational phase, when hygroden fueling will be used to minimize activation and still allow human access.

Particle control in TPX will be provided by eight external cryopumps connected to corimon pumping plenums for the upper and lower divertors. The divertor pumping plenum is defined by the central divertor baffle below the $x$-point as well as the pump ducts to the common manifold ( 8 . ducts top and bottom). Gas enters the plenum from a $6.5 \mathrm{~cm}$ toroidal gap (entrance slot) at the bottom of the central baffle. No pumping is provided at the inner strike point since the pressures there are expected to be much lower. The particle throughput has been calculated using the DEGAS code to track the probability that recycled particles launched from the outer target plate will reach the pump duct given the plasma conditions at the plenum entrance. For typical conditions, only about $5 \%$ of the atomic source is pumped, with the rest being reionized by the divertor plasma; the fraction increases strongly as the slot is made narrower, as can be seen from a simple flux balance argument first used in the design of the DIII-D divertor pump [11]. This is still sufficient to provide a particle throughput of $70 \mathrm{Torr}-1 / \mathrm{s}$ at the nominal operating point. The throughput to the pumps can be varied by changing the strike point position or by throtuling the cryopumps, both of which can be accomplished during the discharge. Argon frosting of the cryopumps will also enable us to carty out helium exhaust studies.

Erosion of the target plate materials should not be a limiting factor for TPX operation. Using the REDEP code [12] we have examined the expected net erosion of the outer target plate for standard operating conditions. These results are summarized in Table 3.

Table 3. Erosion lifetime of possible divertor target materials

\begin{tabular}{|c|c|c|c|}
\hline material & thickness & $\max$ erosion & lifetime to $50 \%$ \\
\hline carbon & $1 \mathrm{~cm}$ & $1.1 \times 10^{-6} \mathrm{~cm} / \mathrm{sec}$ & $4.5 \times 10^{5} \mathrm{sec}$ \\
\hline beryllium & $0.35 \mathrm{~cm}$ & $7.6 \times 10^{-7} \mathrm{~cm} / \mathrm{sec}$ & $2.2 \times 10^{5} \mathrm{sec}$ \\
\hline
\end{tabular}




\begin{tabular}{|l|l|l|l|}
\hline tungnsten & N/A & $3.0 \times 10^{-9} \mathrm{~cm} / \mathrm{sec}$ & machine lifetime \\
\hline
\end{tabular}

The plasma facing components in TPX will have to handle the transients produced by ELMs and disruptions. ELMs should not affect the power handling capability of the device, since we expect them to play a minor mle in the power balance of the discharge. Data from DIII-D shows that, as the heating power increases in H-mode discharges, the frequency of the type I ELMs (formerly called giant ELMs and likely due to exceeding the ideal ballooning mode edge pressure gradient) increases and the amplitude decreases so as to keep $\mathrm{f} \Delta \mathrm{E} \sim 1 \mathrm{MW}$. At the highest heating power, the ELM pulses contain less than $19 \%$ of the stored energy (30MJ in TPX) and should not be a problem. Disruptions will produce larger peak heat loads on the plasma facing components. but with a total stored energy of 3MJ, should be no worse than those in DII-D and JT-60U. The biggest problem with disruptions will be the halo curtent forces, which could reach twice those in DII-D due to the higher toroidal magnetic field.

\section{Radiative divertor operation}

TPX operation at its highest heating power will require a factor of 3-5 reduction in the peak divertor heat flux in order to stay safely below the thermal limits of the cooled structure, since b2 modeling predicts a peak heat flux exceeding $15 \mathrm{MW} / \mathrm{m}^{2}$, and scaling from experiments suggests values above 10. As in ITER, we plan to reduce the heat flux by increasing the radiative losses in the edge, scrape-off layer, and divertor plasmas through impurity plus deuterium gas fueling in the divertor region. Significant heat flux reduction by gas injection has already been demonstrated in a number of divertor tokamaks [13]: the challenge in TPX is to do so while maintaining good core energy confinement and current drive efficiency (low Zeff and high Te). At the highest heating power. the edge plasma temperatures and parallel heat flux will approach values predicted for 
ITER, making this a relevant test of the physics and technology of the radiative divertor concept as a solution for ITER's divertor problem.

So far, we have begun to look at radiative divertor scenarios for TPX using the LEDGE. NEWT-1d, and $b 2.5$ codes. In all of these, the model of the radiation efficiency for impurities allows for non-equilibrium charge-state distributions to develop due to charge-exchange recombination and finite impurity lifetime in the SOL plasma. Both the NEWT-1d and b2.5 codes solve for the self consistent impurity transport in the presence of the background plasma, and the resulting impurity radiation can affect the thermal forces on the impurity ions. While the b2.5 code is fully 2-d, its output diagnostics are still under development.

All three codes predict that increasing the impurity concentration in the divertor will reduce the expected divertor heat flux. We focused on neon and argon because they should be efficient radiators at the low temperatures expected in the divertor region. but poor radiators in the very high temperature core plasma $(\mathrm{Te}(0)=8-10 \mathrm{keV})$. With the LEDGE code, we assumed a constant argon fraction everywhere in the SOL and found that concentrations as high as $7 \%$ were needed to reduce the peak divertor heat flux by a factor of three. With the b2.5 code we are finding that concentrations of neon and argon below $1 \%$ at the plasma midplane can produce signifcant heat flux reductions, though in this case the upstream density on the separatrix had to be increased to greater than $4 \times 10^{19} \mathrm{~m}^{-3}$. We are now looking at the impact of this on curtent drive efficiency.

The NEWT-1d calculations show that is it s possible to use argon injeciton to radiatc nearly all the power flowing in the SOL plasma, though again, the impurity concentration got to be higher than desired. The impurity concentration upstream depends sensitively on the balance between the thermal forces $\left(\propto \nabla T_{\mathrm{e}, \mathrm{l}}\right.$ ) and the frictional forces due to deuteron flow toward the target plates. Fig. Zz shows how the addition of a midplane D2 gas puff to increase the flow velocity in the SOL can reduce the midplane impurity concentration, though at the penalty of higher edge density. Recent experiments on DIII-D have shown that the combination of divertor pumping and midplane fueling can reduce core plasma impurity contamination by factors of three or more [14]. 
The hardware configuration of the TPX divertor is not designed specifically to produce radiative divertor solutions. At present, divertor plasma models do not have the sophistication to show how the machine geometry should be adjusted to inrease the heat flux reduction attainable with impurity or deuterium gas injection. However, we feel that the TPX divertor will help radiative divertor operation by limiting the radial escape of gas from the divertor region and by increasing the divertor recycling. Furthermore. having the ability to quickly (10-20msec time scale) adjust the particle throughput by shifting the strike point away from the entrance to the pumping slot will allow us to better maintain the radiative equilibrium as the heating power or main plasma conditions vary.

\section{Summary}

In this paper we have presented the design philosophy and physics basis for the TPX divertor. As shown, the actively cooled carbon divertor targets should handle the expected peak divertor heat flux for long pulse operation with $18 \mathrm{MW}$ of heating and current drive power. In terms of scrape off layer power density. TPX at first represents only a modest extrapolation from the presently operating DIII-D, JET, and JT-60U, but in terms of cooling technology and particle control requirements, TPX represents a large step towards testing concepts for future reactor-size devices such as TTER and DEMO. Eventually, at its highest heating power. TPX will push edge temperatures and power densities well into the ITER-like regime, where radiative divertor concepts for heat flux reduction need to be tested.

Though we have made a fairly conservative divertor design for MPX, there are still some major concerns which we would like to see resolved by experiments in present divertor experiments. For example. the data on the ability to balance the heat flux and produce wellbehaved heat flux profiles in double null discharges is very sketchy. Recent data [15] from DIII-D suggests that slight magnetic variations may produce non-monotonic heat flux profiles which wouldn't match the contours of the TPX divertor slot. Little information on the scrape-off layer 
thickness in double null plasmas is available. Is the present slot design too narrow? Other data from DHI-D suggests that the in/out power split in single-null configurations may increase with the application of strong divertor pumping [6]. Does this hold for DN as well? If so, it could mean that the heat flux on the inner target will be higher than our design limit. We also need more data on how the divertor geometry will affect radiative divertor performane (e.g., can slots increase the cooling and inhibit contamination of the plasma core?). Improved models will help here as well. Given the short time scale of the TPX design phase and the very stringent cost limits for the project, it is important to get these data as soon as possible.

\section{References}

1. T.H. Osborne, K.H. Burrell, et al., Bull Am. Phys. Soc 38 (1993) 2061.

2. NEWT-1d: R.B. Campbell, J. Nucl. Mater 196-198 (1992) 426.

\section{b2 LEDGE/UEDGE}

3. S.A. Cohen, K.A. Werley, M.F.A. Harrison, et al., J. Nucl. Mater 196-198 (1992) 50.

4. M.E. Fenstermacher, G.D. Porter, M.E. Rensink, T.D. Rognlien, et al. These Proceedings

5. D.N. Hill, A. Futch, A.W. Leonard, M.Ali Mahdavi, et al, J. Nucl. Mater 196-198 (1992) 204.

6. R. Maingi, P.K. Mioduszewski, M. Ali Mahdavi, J.W. Cuthbertson, et al. These Procedivigs

7. K. Itamai, M. Shimada and N. Hosogane. J. Nucl. Mater 196-198 (1992) 755.

8. D.N. Hill, T.W. Petrie, S.L. Allen, et al, Bull Amer. Phys. Soc. 38 (1993) 20607 S11.

9. ASDEX: J. Neuhauser, R. Aratari, et al, in Plasma Physics and Controlled Nuclear Fusion Research 1989 (Proc. 13 Conf. on Plasma Phys. Cont. Fusion Res. Washington, USA 1989). PDX: M.G. Bell, R.J. Fonck, et al., J. Nucl. Mater 121 (1984) 132.

10. P.M. Anderson, C.B. Baxi, E.E. Reis, L.D. Sevier, et al., Proc. IEEE Symposium Fusion Eng. Cape Cod, MA (1993). General Atomics Rep. GA-A21411, Oct. 1993. 
11. P.K. Mioduszewski. W.L. Owen, M.M. Menon, and J.T. HOgan, J. Nucl. Mater 176\&177 (1990) 733.

12. J. N. Brooks, Fus. Technology 18 (1990) 239.

13. C-Mod: B. Lipschultz, et al., These Proceedings. DIll-D: T.W. Petrie. D.N. Hill. et al.. Proc. 18th European Conf. on Cont. Fusion, Berlin (1991) III-237. JET: D. Stork. A. Tanga, B. Tubbing, et al., Bull. Am. Phys. Soc. 34 (1989) 2055. JT-60U: N. Hosogane. Phys. Fluids B 5 (1993) 2417.

14. M.J. Schaffer, N.H. Brooks, J.W. Cuthbertson, et al. Bull Am. Phys. Soc. 38 (1993) 2058.

15. T.E. Evans. C.J. Lasnier, D.N. Hill, A.W. Leonard, et al, These Proceedings.

\section{Figure Captions}

Fig. 1 Cross section of the lower divertor of TPX showing major plasma facing components.

Fig. 2 (a), Radial protiles of $n_{e, d i v}, T_{e, d i v}$ and $q_{d i v}$ across the outer divertor target. (b), profiles along a SOL field line just outside the separatrix. 

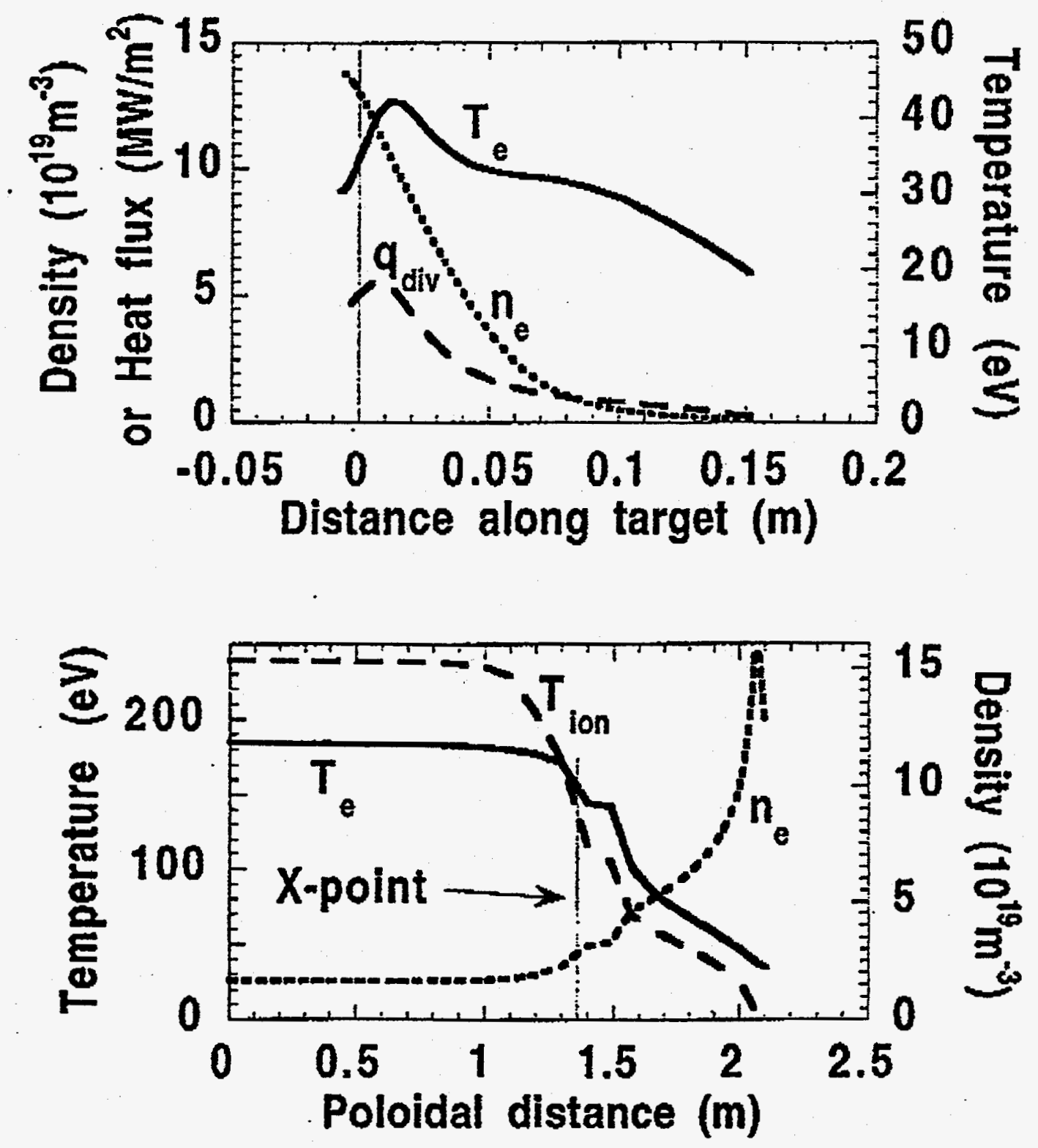


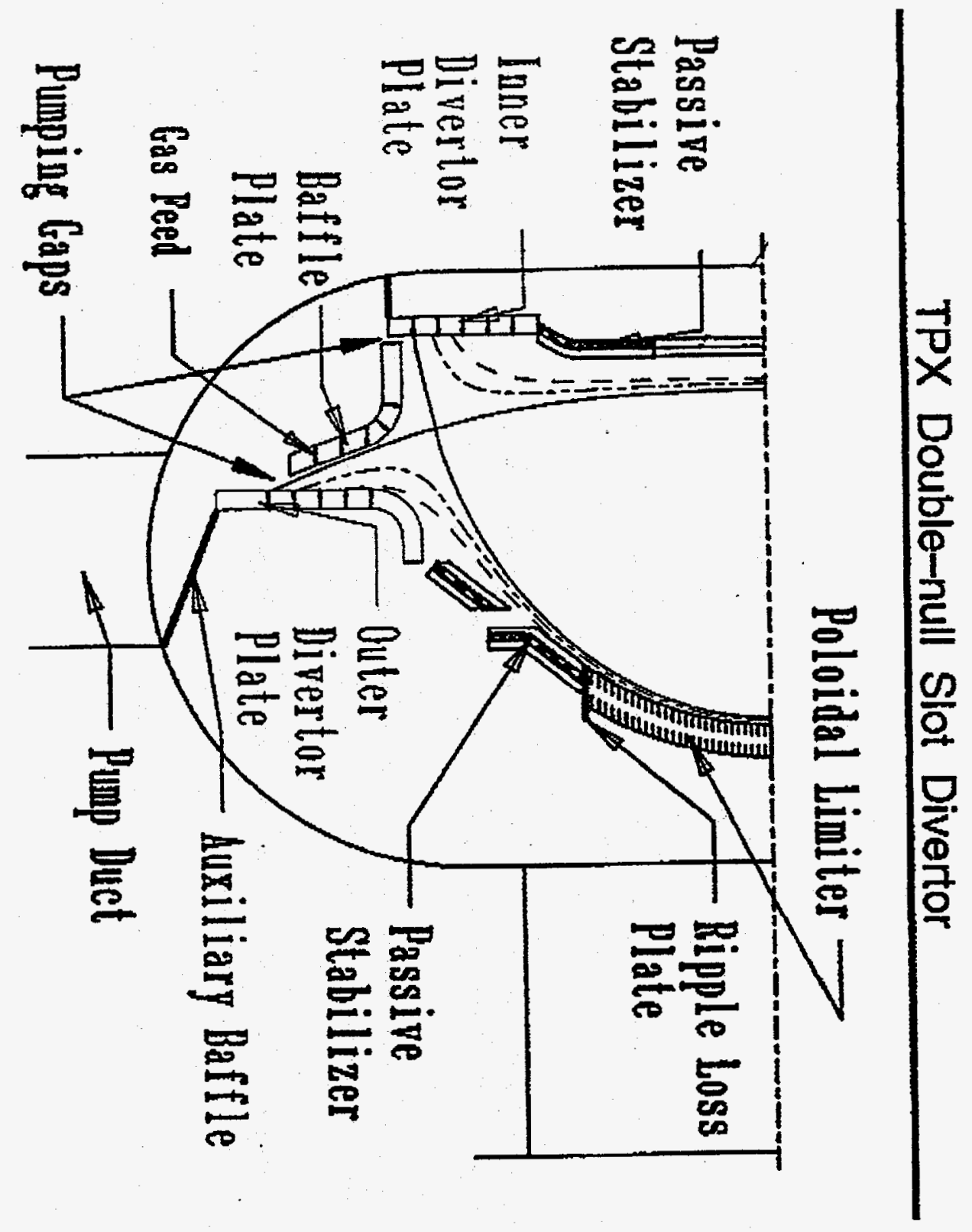




\section{DIVERTOR DESIGN FOR THE TOKAMAK PHYSICS EXPERIMENT *}

Work performed by the TPX Coceptual Design Team

Presented by

David N. Hill

Lawrence Livermore National Laboratory

In this paper we discuss the present divertor design for the planned TPX tokamak, which will explore the physics and technology of steady-state ( 1000 s pulses) heat and particle removal in high confinement $(2-4 \times L$-mode $)$, high beta $\left(\beta_{N} \geq 3\right)$ divertor plasmas sustalned by non-inductive current drive. The TPX device will operate in the double-null divertor configuration, with actively cooled graphite targets forming a deep $(0.5 \mathrm{~m})$ slot at the outer strike point. The peak heat flux on the highly tilted $\left(74^{\circ}\right.$ from normal) re-entrant (to recycle lons back toward the separatrix) will be in the range of $4-6 \mathrm{MW} / \mathrm{m}^{2}$ with $18 \mathrm{MW}$ of neutral beam and RF heating power. The combination of active pumping and gas puffing (deuterium plus impurities), along with higher heating power (45 MW maximum) will allow testing of radiatlve dlvertor concepts at ITER-like power densities.

11th International Conf. on Plasma Surface Interactions 23-27 May, 1994

Mito, Japan

"Work was performed under the auspices of the U.S Department of Energy by Lawrence Livermore National Laboratory under Contract $W-7405-E N G-48$ and by General Atomics urder Contract $D E-$ AC02-76-CHO-3073. 


\section{TPX OBJECTIVES}

The mission of the TPX is to develop the scientific basis for an economical, more compact, and continuously operating tokamak fusion reactor.

Toward these ends, our goals are to obtain:

1. Efficient current drive via high bootstrap fraction (NBCD, LHCD, and FWCD)

2. Advanced tokamak operation:

$\beta_{N}=4-5$ and $H=3-4$ at $q_{95} \sim 4$

3. Simultaneous with $1 \& 2$, steady-state power and particle exhaust, extrapolation to $\sim 3 \mathrm{MW} / \mathrm{m}^{2}$ neutron flux \& $10 \%$ He ash.

- High plasma and component reliability: $80 \%$ availability of all components, $\sim 1$ disruption per 10 hours operation. 


\section{Tokamak Parameters}

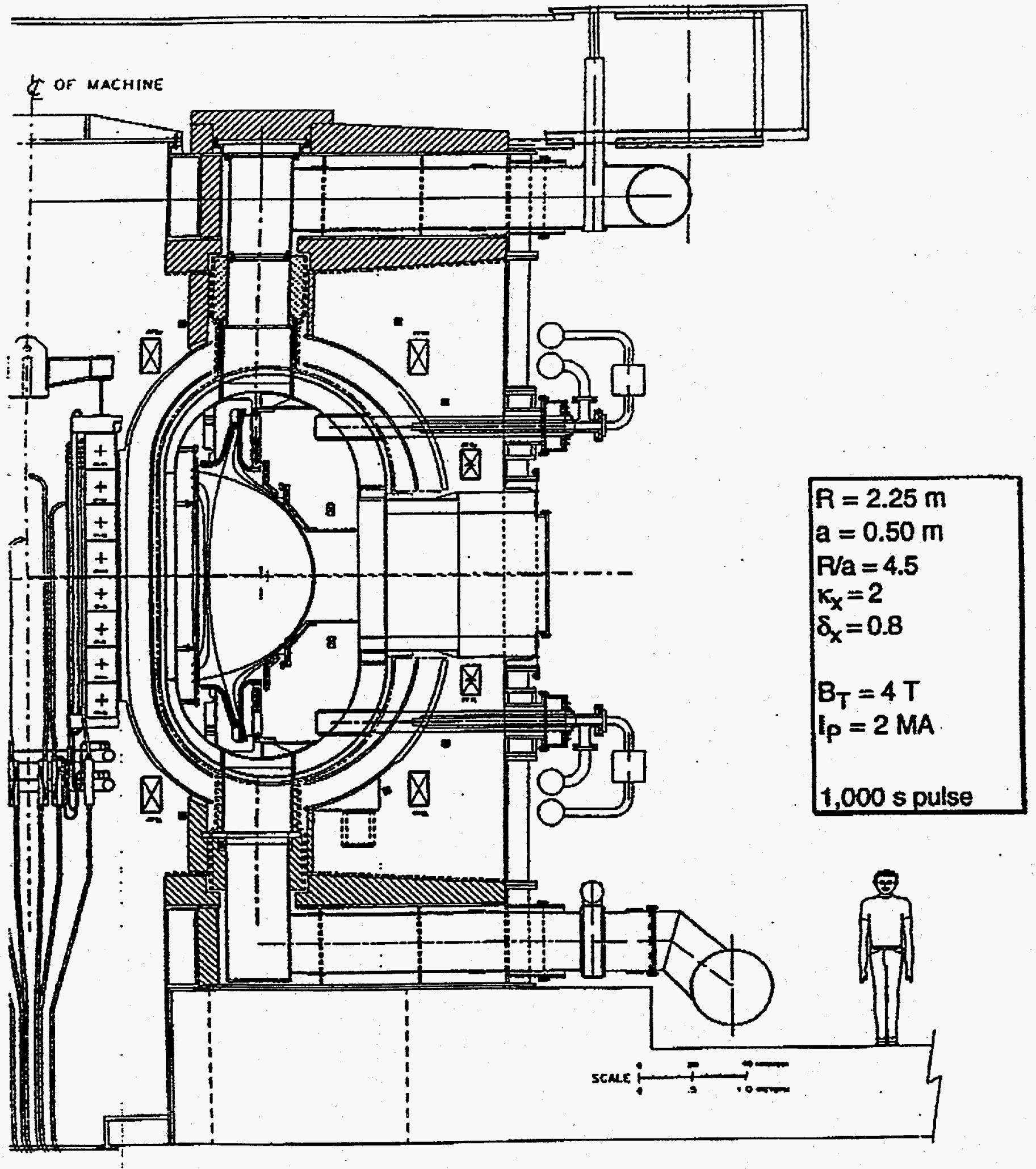




\section{TPX HAS A DEEP DOUBLE-NULL DIVERTOR}

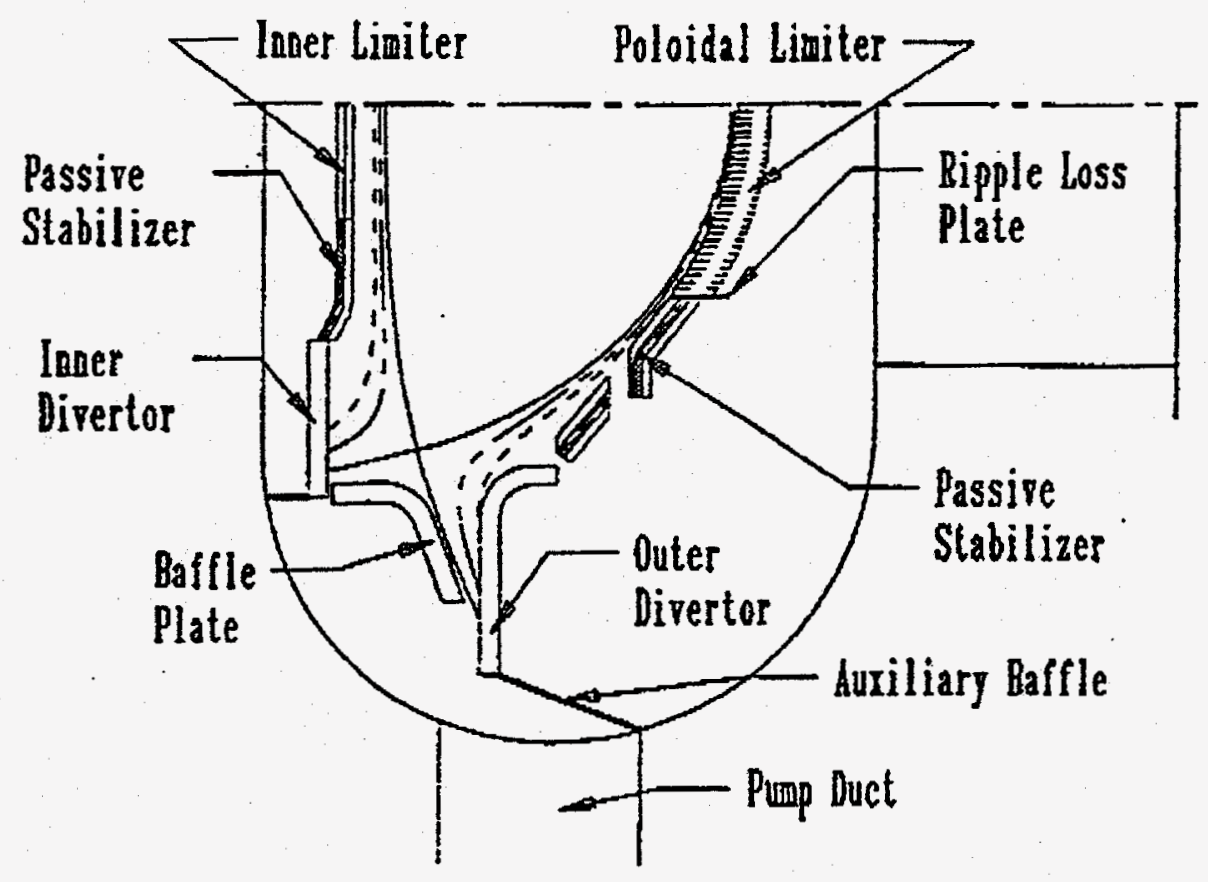

- Double-null, high $K$ and $\delta$ shape improves confinement and stability and maximizes divertor area.

- A re-entrant slot design lowers the peak heat flux and maximizes recycling (lower net erosion). No radiative solution needed for reliable startup and operation.

- Baffle isolates inner and outer divertor leg.

- Pumping plenum entrance slot situated to maximize throughput. Plasma motion and external throttling regulate pumping and divertor pressure. 
EXPECTED DIVERTOR HEAT FLUX (simplest possible calculation)

- $P_{\text {in }}(M W)=$

- $\mathfrak{f}_{\text {rad }}=$

$0.4 \quad 0.4$

- DND: $P_{\text {out }}^{\text {div }}(M W)=0.8 \times 0.55 \times(1-0.4) \times 18$

4.7512

SND: $P_{\text {out }}^{\text {dlv }}(M W)=0.67 \times(1-0.4) \times 18$ (1.5x higher than DND)

$\lambda_{\mathrm{q}}$ at midplane $(\mathrm{cm})$

$7 . 2 \longdiv { 1 8 }$

$\lambda_{\mathrm{q}}$ at divertor $\left(\lambda_{\mathrm{q}, \mathrm{dlv}}\right)(\mathrm{cm})$

$\left[=\lambda_{q} \times 2.5 \times 1 / \sin \left(16^{\circ}\right)=9.1 \lambda_{q}\right]$

$R_{\text {div }}(m)$

$q_{\text {max }}=\frac{P_{d I v}}{2 \pi R_{\text {div }} \lambda_{\text {g,div }}}\left(M W / m^{2}\right)$

with a correction for diffusion into private

0.50 .5 flux region $(0.5-0.7)$ 


\section{ACCEPTABLE DIVERTOR CONDITIONS SHOULD BE OBTAINED WITH THE BASELINE HEATING COMPLEMENT}

- With $18 \mathrm{MW}$, TPX should be in the marginally collisional flux-limited regime. Ions and electrons are not fully equilibrated in the SOL.
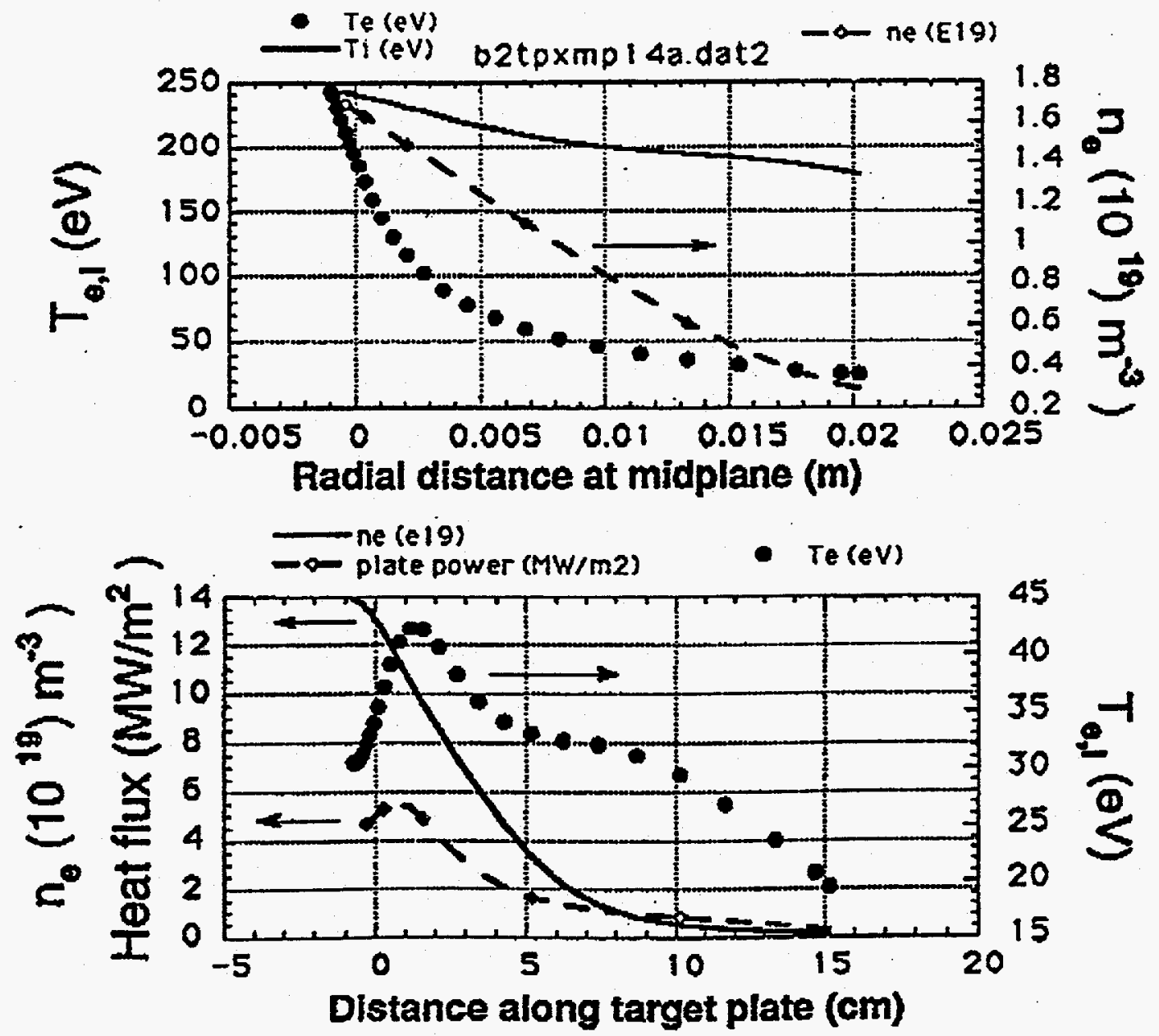


\section{A RE-ENTRANT DIVERTOR TARGET IS}

\section{BETTER}

Inward plate tilt preferentially reflects neutrals back towards the separatrix, yielding a higher density and lower temperature divertor plasma.
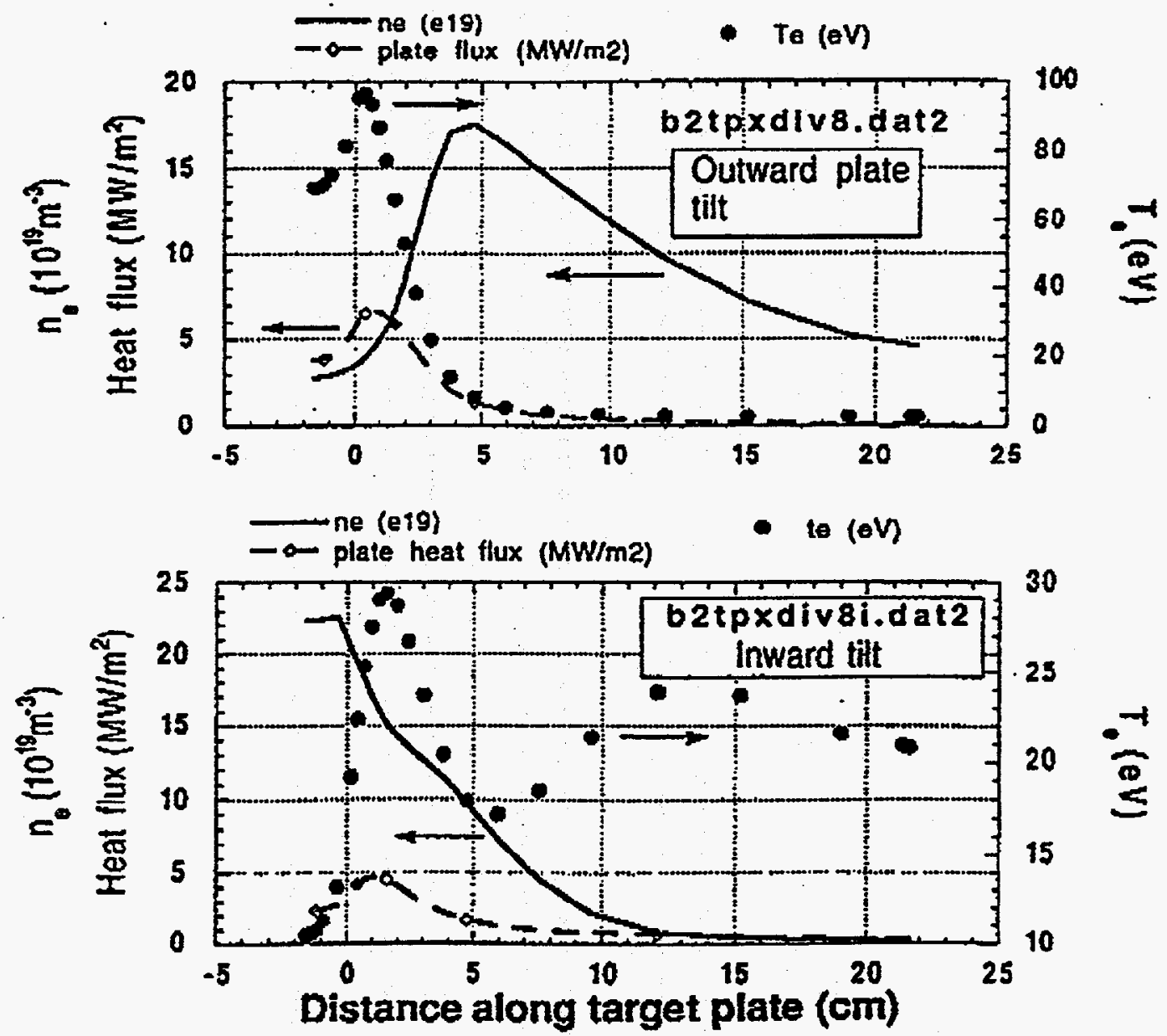

- These results also show that $T_{\mathrm{e}, \mathrm{div}}$ is very sensitive to changes in the neutral transport model. 


\section{EXTRAPOLATION FROM EXISTING EXPERIMENTS}

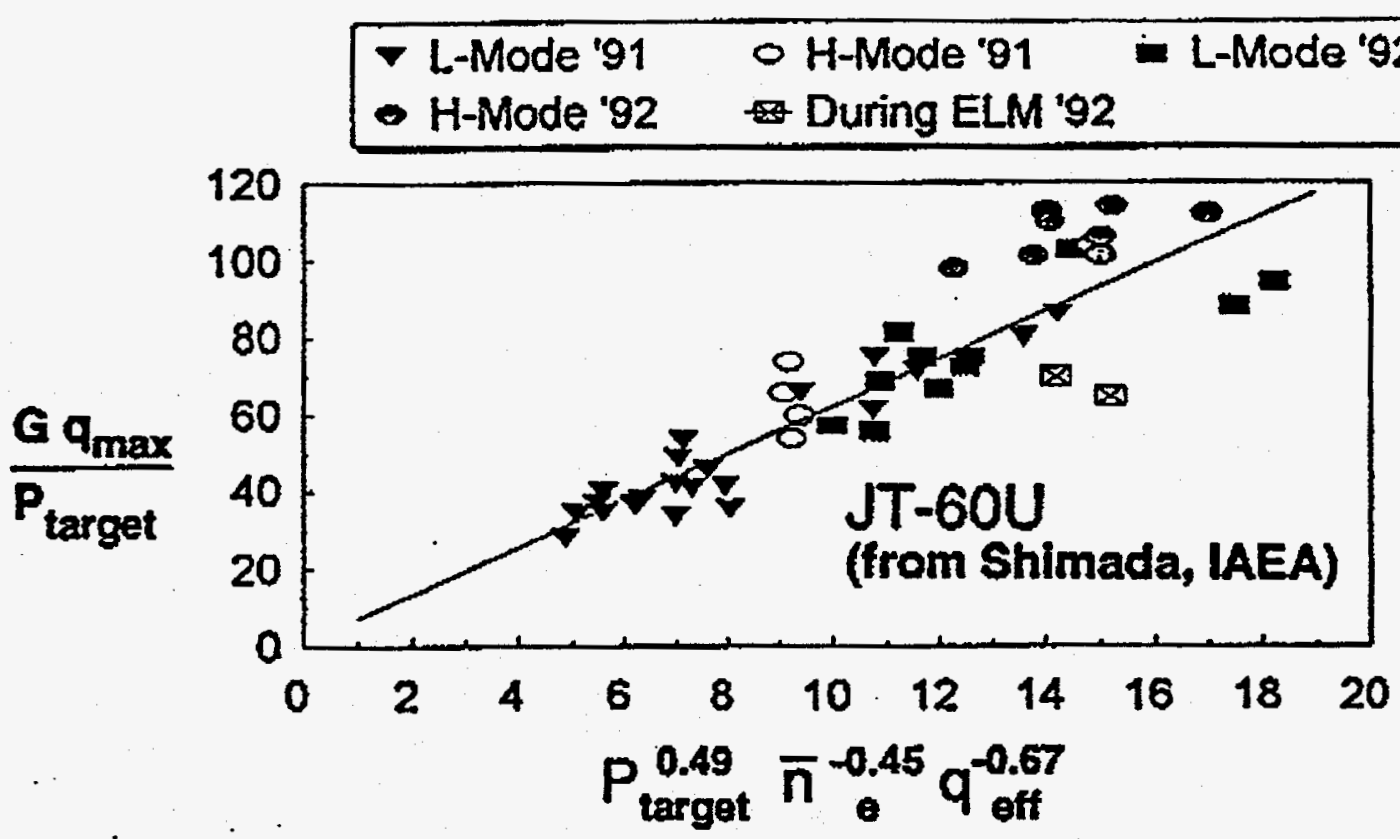

Applying this scaling we obtain a peak heat flux of $3.0 \mathrm{MW} / \mathrm{m}^{2}$ for TPX with $18 \mathrm{MW}$.

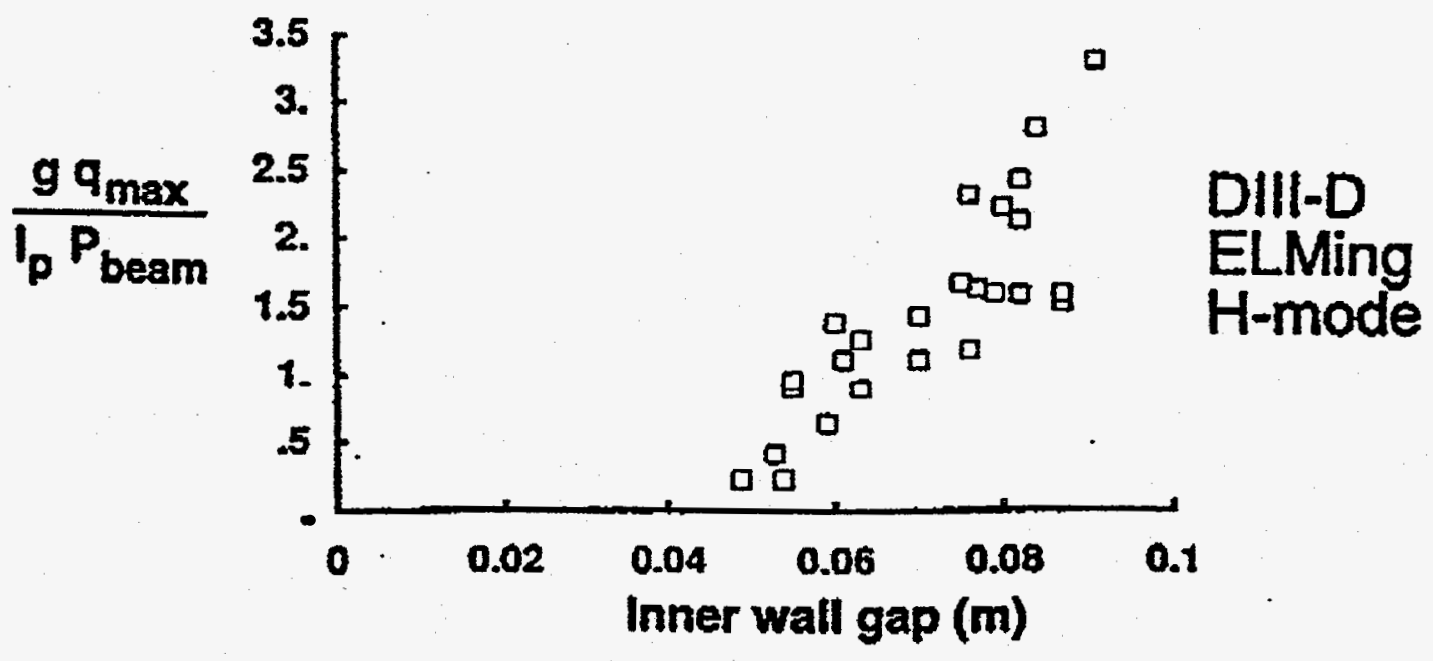

Using these data gives $2.5 \mathrm{MW} / \mathrm{m}^{2}$ for TPX. 


\section{5}

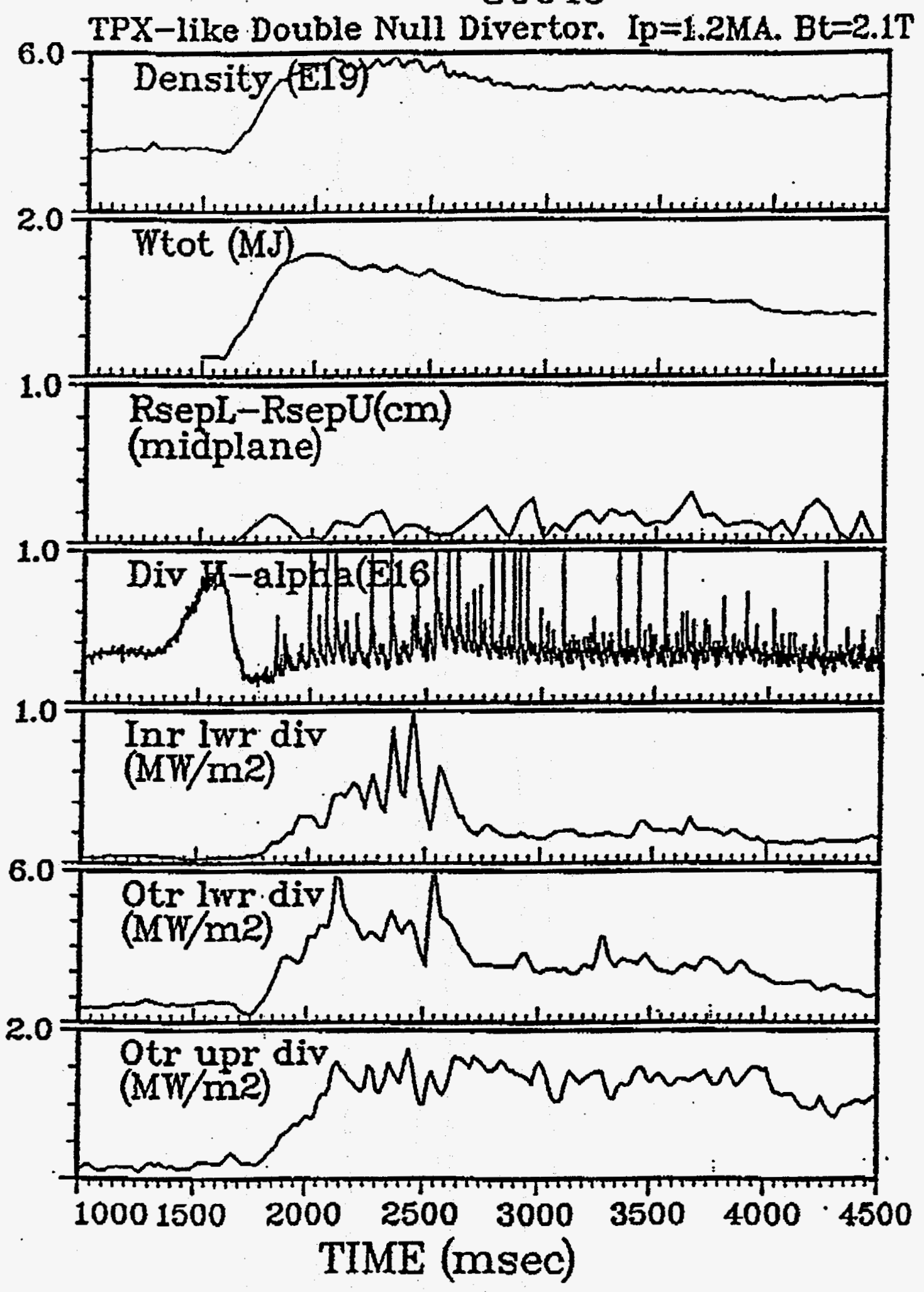




\section{TOROIDAL ASYMMETRIES IN DIII-D}

(during locked modes - so far)
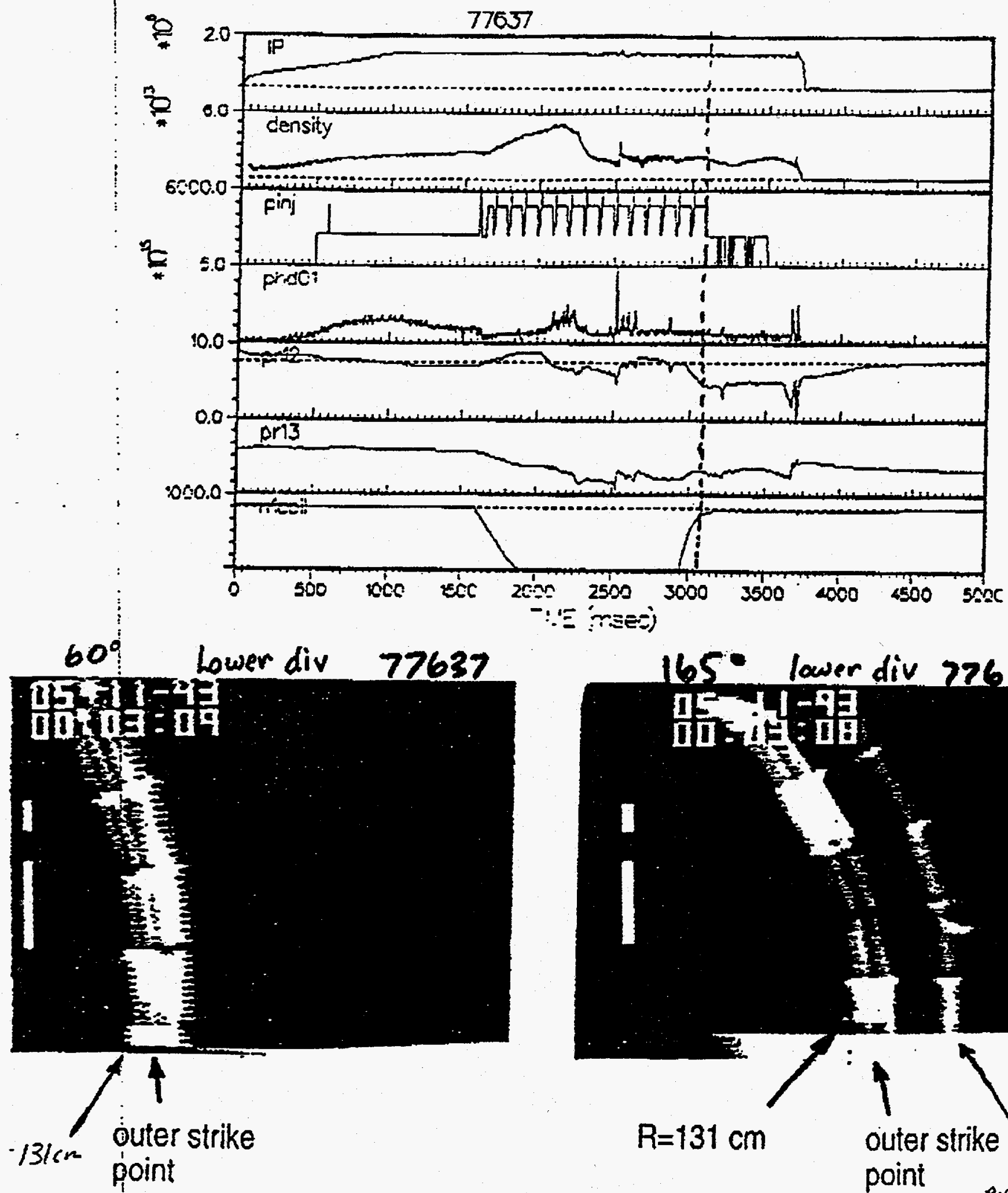

Increasing major sadius

165 - lower div 72677
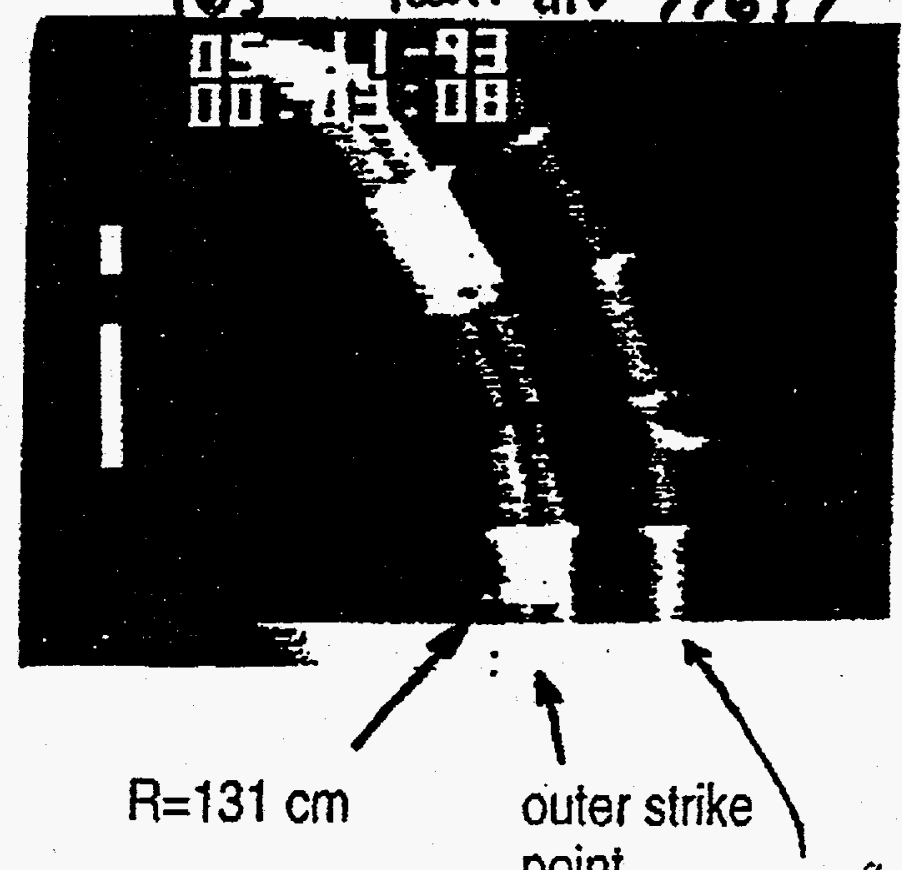

point

extraflux

at this

toradal ops: : : = lo 


\section{PFC PEAK DESIGN HEAT LOADS and}

MATERIAL CHOICES

\begin{tabular}{|l|l|l|}
\hline \multicolumn{1}{|c|}{ Component } & \multicolumn{1}{|c|}{$\begin{array}{c}\text { Peak Power for } \\
18 \mathrm{MW} \\
\left(\mathrm{MW} / \mathrm{m}^{2}\right)\end{array}$} & $\begin{array}{c}\text { Peak Power for } \\
45 \mathrm{MW} \\
\left(\mathrm{MW} / \mathrm{m}^{2}\right)\end{array}$ \\
\hline Divertor targets & $15(7.5)$ & $15(7.5)$ \\
\hline Divertor baffle & 4 & 4 \\
\hline Inboard limiter & 0.15 & 0.4 \\
\hline QNBl strike point & 1.45 & 1.7 \\
\hline Outboard limiters & 0.15 & 0.4 \\
\hline Neutral beam armor & 2.7 & 3.8 \\
\hline Ripple armor & 0.72 & 2.1 \\
\hline
\end{tabular}

Active water cooling is required.

Carbon-fiber composite materials are preferred for all high heat flux and disruption-damage locations:

- high thermal conductivity

- excellent disruption resistance

- low Z

- lots of operating experience

- longer erosion lifetime than Be 


\section{TPX PLASMA FACING COMPONENTS}

\section{low activation}

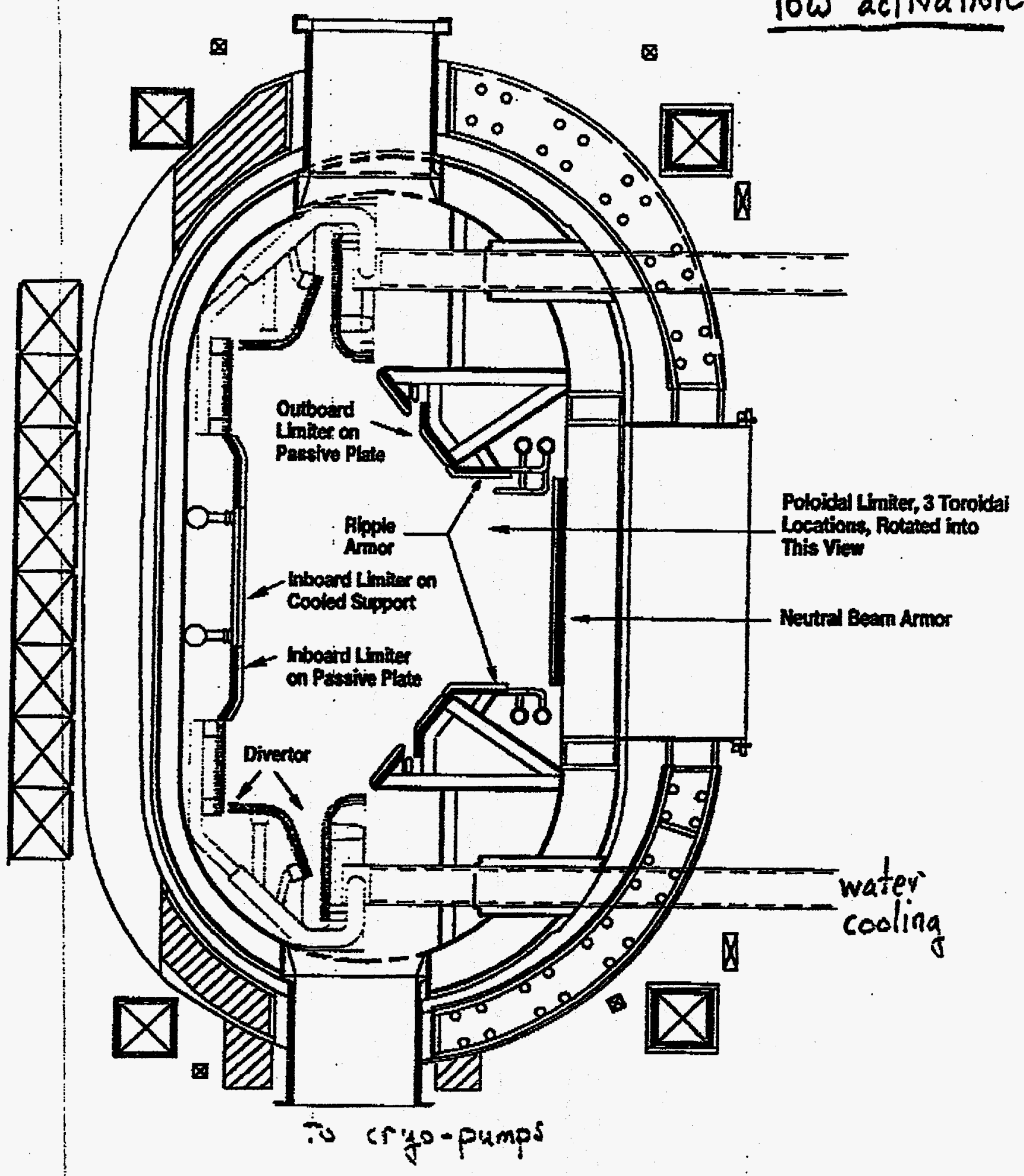




\section{INBOARD LIMITER PANEL}

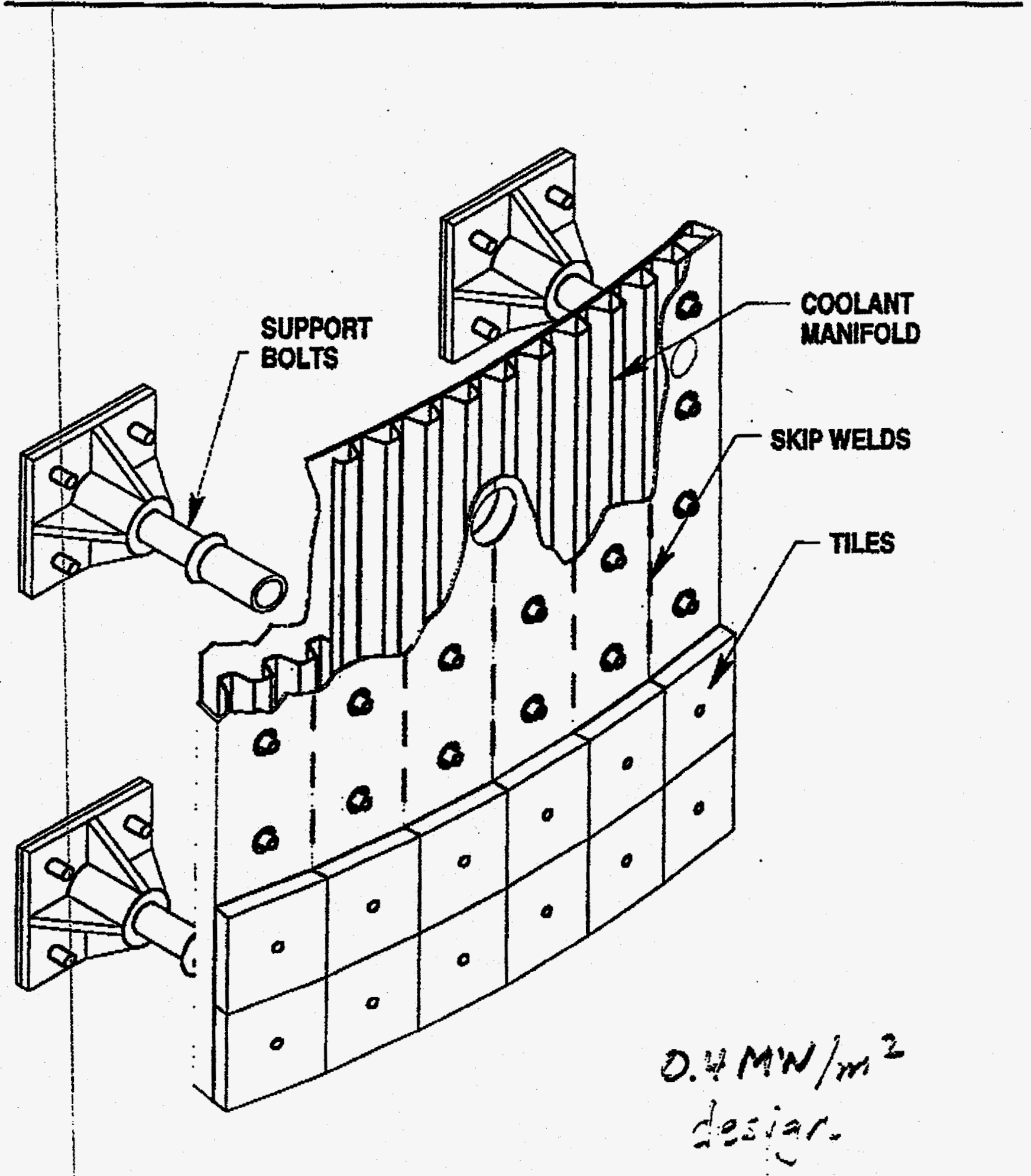




\section{IN-VESSEL MANIPULATOR} [SHOWN WITH TELEMATE (SM-229): DEXTROUS ARM]

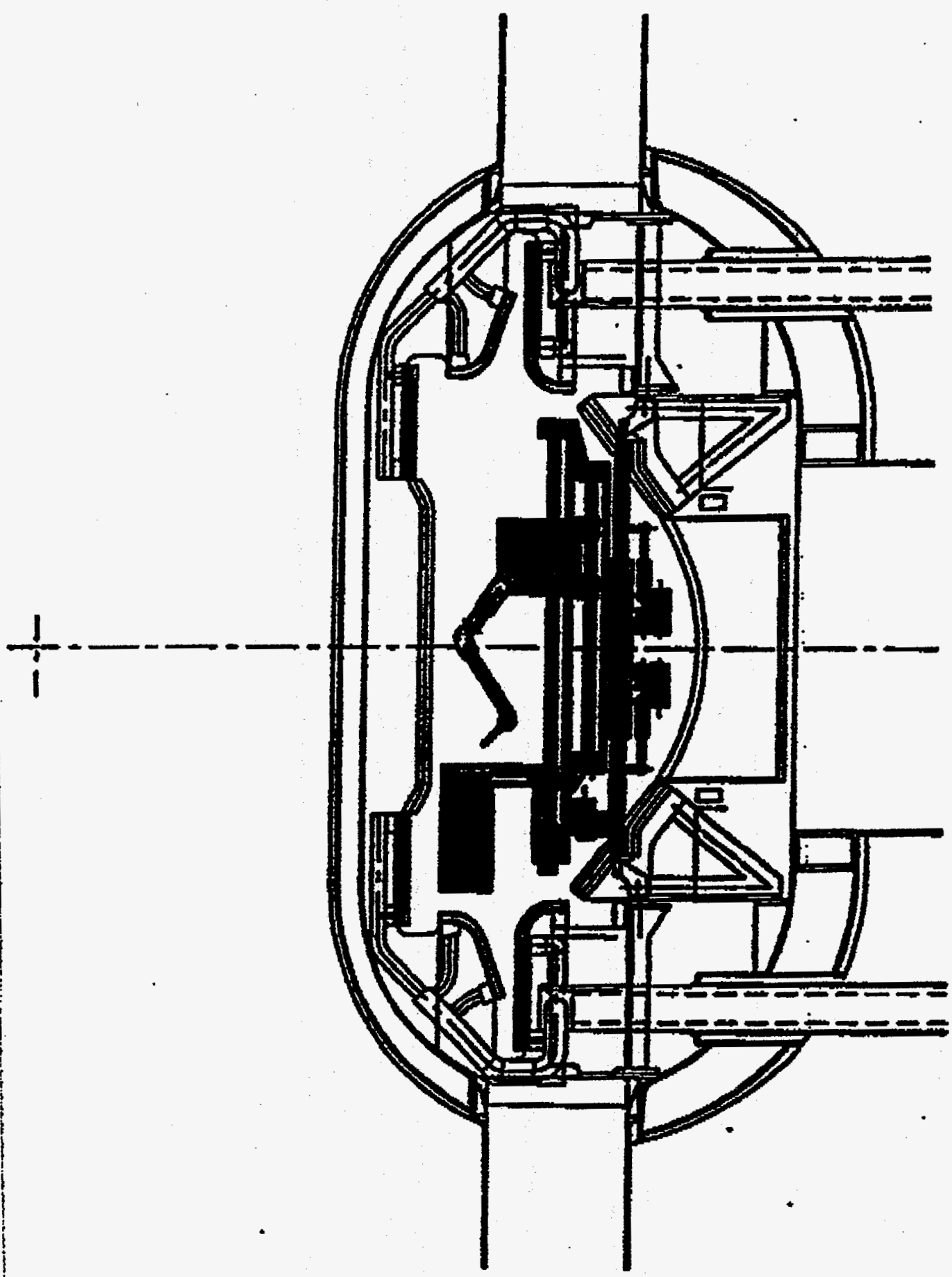




\section{DIVERTOR-PLATE EROSION LIFETIME}

Erosion calculated using the REDEP code (Brooks, ANL), with plasma conditions in front of the surfaces obtained from the Braams b2 code.

For the standard $18 \mathrm{MW}$ operating scenario we have:

$-\mathrm{T}_{\mathrm{s}}=42 \mathrm{eV}, \mathrm{T}_{\mathrm{i}}=100 \mathrm{eV}, \mathrm{T}_{\text {pite }}=1200 \mathrm{C}$, and $\mathrm{n}_{\mathrm{e}}=1.4 \times 10^{19} \mathrm{~m}^{-3}$

$-9.0 \times 10^{4} \mathrm{sec} / \mathrm{mm}$ for carbon

$-1.3 \times 10^{5} \mathrm{sec} / \mathrm{mm}$ for beryllium

$->3.3 \times 10^{7} \mathrm{sec} / \mathrm{mm}$ for tungsten

- expected operating time is $\leq 5 \times 10^{5} \mathrm{sec} /$ year

Note that the lifetime of a carbon divertor could be as much as twice as long as a beryllium divertor because the higher thermal conductivity of CFC allows for much thicker armor (10 $\mathrm{mm}$ vs. $3.5 \mathrm{~mm}$ ). 


\section{PARTICLE EXHAUST}

Beam fueling:

fast atoms -

$0.8 \times 10^{20}$ particles/s/MW

cold gas -

$0.8 \times 10^{20}$ particles/s/MW

total beam fueling (24 MW) -

$2.8 \times 10^{21}$ particles/sec

(43.5 Torr $/ \mathrm{s}$ )

Plasma fueling:

$$
N=\frac{N(1-R)}{\tau_{p}}=\frac{N}{\tau_{p}^{*}}
$$

Assume $R=0.5, \tau_{p}=2 \tau_{E}=0.4 \mathrm{~s}, \tau_{p}^{*}=4 \tau_{E}$

then

$$
N=2.5 \times 10^{21}=36 \text { Torr } 1 / \mathrm{s}
$$

We are designing the pumping system to have a throughput of $85 \mathrm{Torr} \mathrm{V} / \mathrm{s}$ at a divertor plenum pressure of $1 \mathrm{miTorr}$.

DEGAS modeling using b2 plasma and realistic pump geometry shows that such exhaust rates can be obtained by pumping at the outer strike point only. 


\section{WALL CONDITIONING}

We require that the TPX vacuum vessel be baked to $350^{\circ} \mathrm{C}$.

Based on experience from DIII-D, JT-60U, and JET, the operating temperature of the vessel will be below $150^{\circ} \mathrm{C}$.

Pulse discharge cleaning between shots is also being studied.

Experiments with cryo-pumping inTore Supra: and DIll-D show that it is possible to reduce the gas inventory in the carbon walls of the tokamak by pumping on the plasma during the pulse. This suggests that future long-pulse, actively pumped devices may not need preliminary GDC before the start of each discharge. 


\section{MW OPERATION WILL PRODUCE}

REACTOR-LIKE EDGE PLASMAS AND REQUIRE A RADIATIVE DIVERTOR
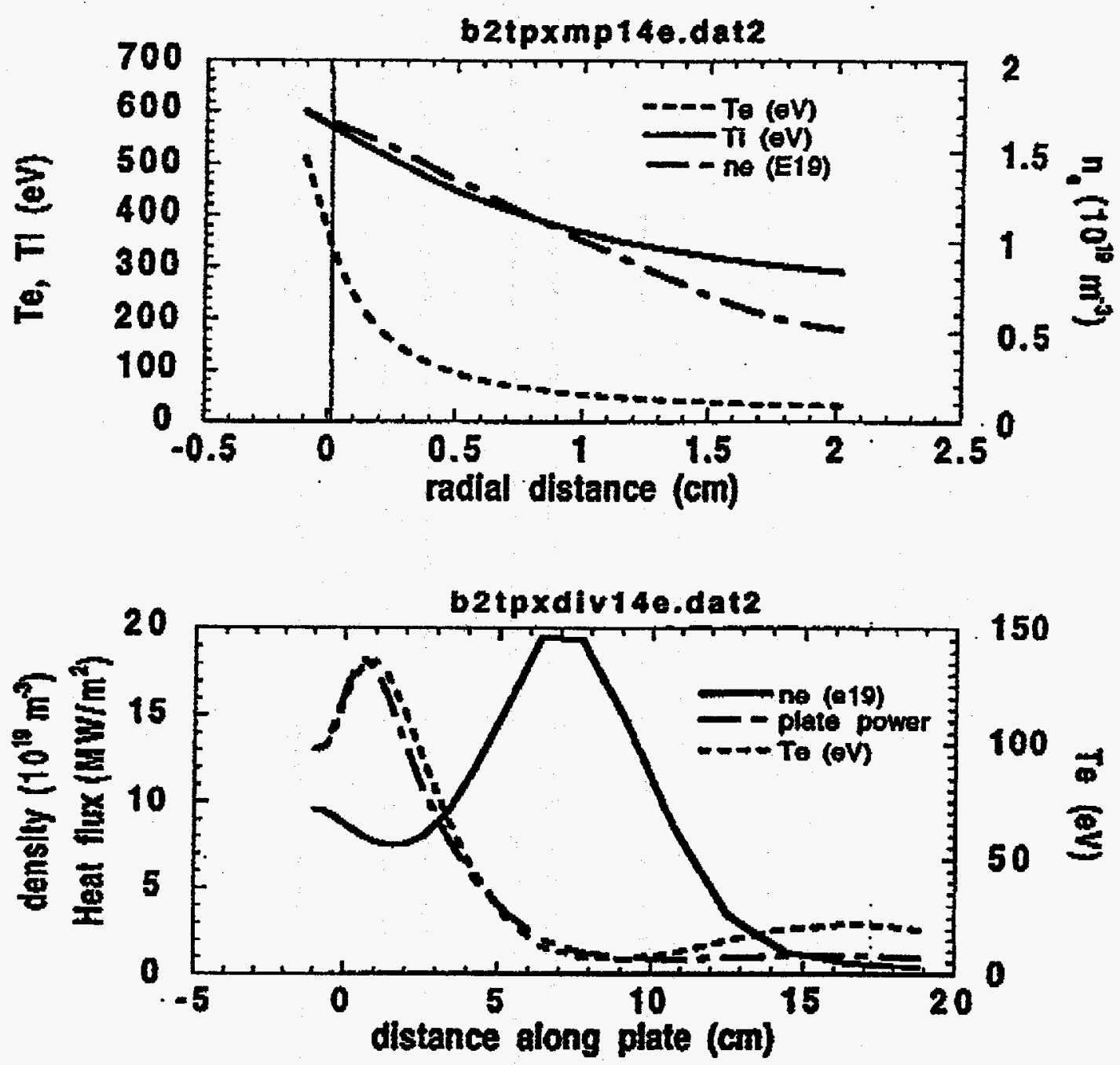

Upstream values are comparable to thase predicted for ITER. 


\section{TPX RADIATIVE DIVERTOR DEVELOPMENT}

Initial design is compatible with present experimental results regarding heat flux reduction: deep slot to improve isolation from core, gas valves to puff (match core eflux), and pumps to regulate conditions and maintain steady-state.

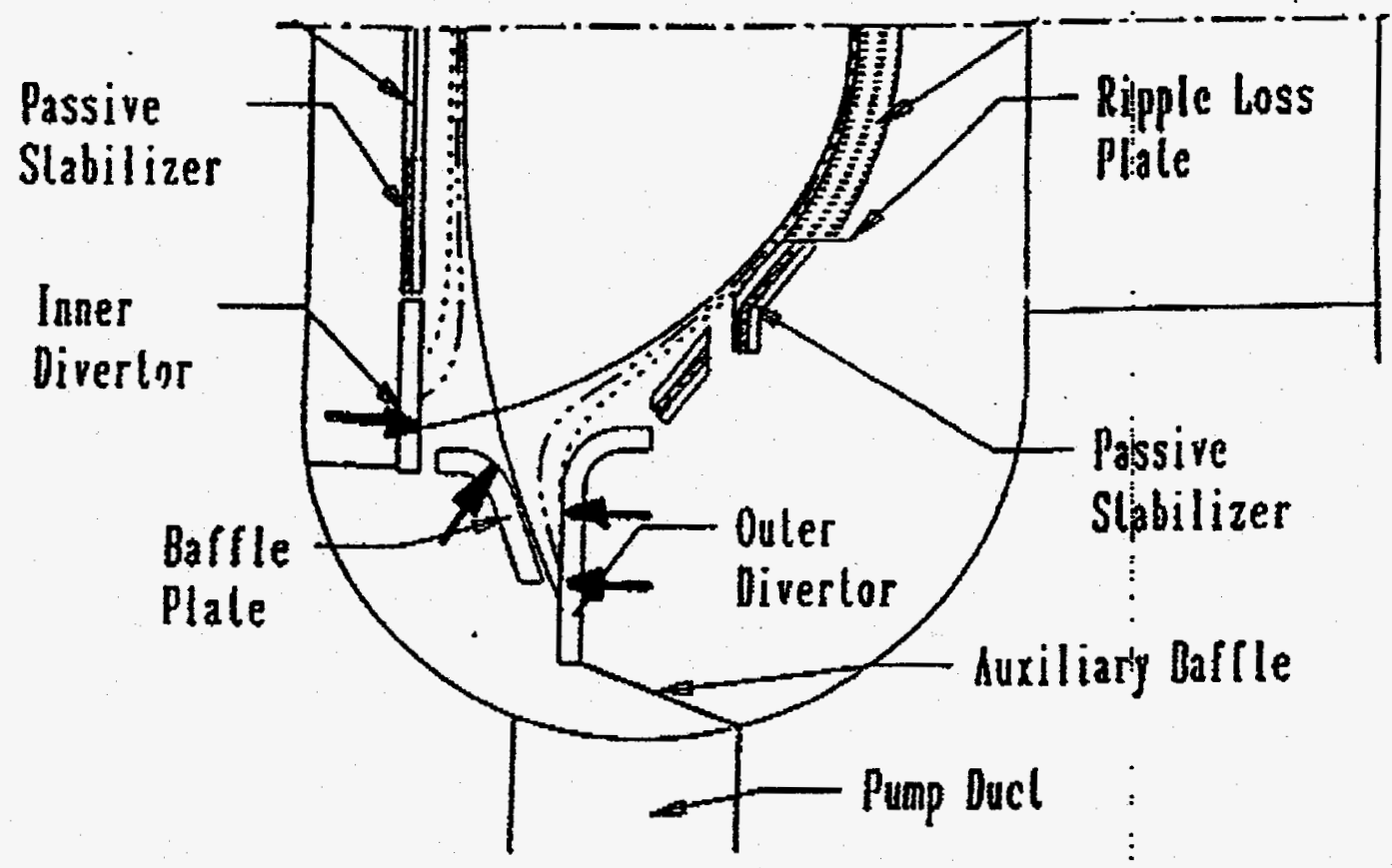

Factor of three reduction required to support advanced tokamak experiments at high power, but factor of 10 desired to relate to ITER.

Expected plasma temperatures similar to ITER, so impurity radiation may be similar (e.g, location and magnitude of peak radiative loss).

Machine has space and capability to modify divertor structure based on predictive-model development or new experimental results. 


\section{SUMMARY}

The TPX tokamak will test the compatibility of steady-state power and particle control techniques with advanced tokamak operation (non-inductive current drive with high beta and high confinement).

A deep double-null divertor configuration is planned to enhance recycling at the target plate, spread out the heat flux, and facilitate pumping for density control.

The carbon-carbon composite materials used for PFC construction should provide reliable operation with the initial heating complement, but considerable component testing will be required.

High power operation will require active reduction of the peak divertor heat flux: l.e., a dissipative divertor concept. Such a concept is now being tested in operating tokamaks. 


\section{Introduction}

Work is underway to complete the design of the TPX tokamak (Tokamak Physics Experiment), which could begin operation in 1999-2000. The mission of TPX is to explore attractive steady-state reactor regimes (i.e., having pulse lengths much longer than the equilibration times for the current profile or the plasma-wall interactions) with high confinement $(H \geq 2$, where $H$ is the enhancement factor over $L$-mode scaling) and high plasma pressure $\left(\beta_{N} \geq 3.0\right.$, where $\beta_{N}$ is Troyon factor $\mathrm{V} / \mathrm{aB}$ ). Present experiments [1] suggest that such conditions can be best achieved in divertor plasmas with high elongation and triangularity, with good density control to permit efficient cursent drive and current-profile control. Thus, a double-null (DN) divertor configuration has been selected, though the hardware has been designed to allow for single-null operation as well. In this paper we present an overview of the proposed TPX divertor including the physics basis for our design choices and a description of the hardware's capability to meet the system requirements.

TPX is being designed as a long-pulse tokamak ( $\left.\tau_{\text {puise }}=1000 \mathrm{sec}\right)$ with superconducting magnets and auxillary heating suitable for current drive experiments at power levels from 17-45 MW. The heating systems available during initial operation will include $8 \mathrm{MW}$ of neutral beams. 8MW of ion cyclotron RF heating, and 1.5 MW of lower hybrid hesting/current drive. Baseline machine parameters and typical initial operating conditions expected for the main plasma are contained in Table 1. Because of the expected improvement in performance (higher confinement. plasma temperature, and current drive efficiency), most long-pulse operation will take place with dcuterium plasmas and deuterium neutral beam injection. The resulting neutron production will necessitate the use of low activation materials such as titantium for the vacuum vessel, and remote handling techniques such as an in-vessel robot manipulator.

Table 1. Baseline TPX Machine and Plasma Parameters

\begin{tabular}{|l|l|l|}
\hline$R=2.25 \mathrm{~m}$ & $\mathrm{a}=0.5 \mathrm{~m}$ & $\kappa_{x}=1.6-2, \delta_{x}=0.8$ \\
\hline$B_{T}=4 \mathrm{~T}$ & $I_{p}=1.6-2 \mathrm{MA}, 995=3-5$ & $\tau_{\text {pulse }}=1,000 \mathrm{sec}$ \\
\hline
\end{tabular}

